УДК 536.24

DOI

\title{
ТЕМПЕРАТУРНЫЙ РЕЖИМ МОНОГРАНУЛИРОВАНИЯ ПРИ ПРОИЗВОДСТВЕ ИМИТИРОВАННЫХ ПИЩЕВЫХ ПРОДУКТОВ
}

\author{
Басок Б.И., д. т. н, профессор, Давыденко Б.В., д. т. н, ст. н. с., Тимощенко А.В., к. т. н. \\ Институт технической теплофизики НАН Украины, г. Киев
}

\begin{abstract}
Аннотация. В связи с дефицитом и высокой стоимостью продуктов из ценных видов рыбы существует необходимость в производстве их аналогов, которые по пищевой иенности и вкусовым качествам не уступали бы натуральным продуктам. Один из способов производства аналога икры зернистой черной состоит в монодисперсном дроблении струи раствора, приготовленного на основе белка куриньх яиц с натуральными рыбными добавками и черным пищевым красителем. Капли раствора направляются в грануляционную колонну, где происходит их нагрев до температуры начала термической коагулячии его белкового компонента. Важными проблемами, возникающими при производства гранулированных продуктов по данной технологии, являются создание изотермических условий в грануляционной колонне и уменьшение потерь теплоты с ее поверхности с иелью повышения энергетической эффективности данного производства. Для решения данных проблем методом численного моделирования исследован температурный режим грануляционной колонны при производстве имитированных моногранулированных пищевых продуктов. Путем численного решения системы уравнений гидродинамики и теплопереноса для потока формующей жидкости получены распределения скорости и температуры в грануляционной колонне. Найдено расстояние, которое должна пройти частица в грануляиионной колонне для завершения процесса ее гелирования. Показано влияние теплоизоляции колонны на потери теплоты с ее поверхности.
\end{abstract}

Ключевые слова: моногранулирование, имитированные пищевые продукты, грануляционная колонна, теплообмен, теплоизоляция.

\section{TEMPERATURE REGIME OF MONOGRANULATION IN THE PRODUCTION OF IMITATED FOOD PRODUCTS}

Basok B.I., Davydenko B.V., Timoshchenko A.V. Institute of Engineering Thermophysics of the NAS of Ukraine, Kiev

\begin{abstract}
Due to the scarcity and high cost of products from valuable species of fish, there is a need to produce their analogues, which in terms of nutritional value and taste would not be inferior to natural products. One of the methods for producing analogue of black caviar consists in the monodisperse crushing of a jet of solution prepared on the basis of the protein of chicken eggs with natural fish additives and black food coloring. Drops of the solution are sent to the granulation column, where they are heated to the temperature of the beginning of thermal coagulation of its protein component. The creation of isothermal conditions in the granulation column and the reduction of heat losses from its surface in order to increase the energy efficiency of the production are important problems encountered in the production of granulated products using this technology. To solve these problems, the temperature regime of the granulation column in the production of imitated monogranular food products has been studied using a numerical simulation method. By numerical solution of the system of equations of hydrodynamics and heat transfer for the flow of the forming liquid, the velocity and temperature distributions in the granulation column are obtained. The distance that a particle must pass in the granulation column to complete its gelling process has been found. The effect of thermal insulation of a column on heat loss from its surface is shown.
\end{abstract}

Key words: monogranulation, imitated food products, granulation column, heat transfer, heat insulation.

Введение. В настоящее время активно развиваются технологии производства искусственных пищевых продуктов, которые заменяют натуральные и не уступают им по качеству и питательным свойствам. Это непосредственно относиться к аналогам продуктов из ценных видов рыбы, популяция которых ежегодно снижается из-за неконтролируемого вылова и ухудшения экологической ситуации. Среди таких продуктов следует выделить имитированную черную и красную икру.

Анализ проблематики и последних публикаций. Одна из технологий производства имитированных пищевых продуктов, в том числе аналога черной зернистой икры, связана с процессами моногранулирования и термоформования. Исходная рецептурная смесь для данного продукта создается на основе белка куриных яиц. Она также содержит натуральные вкусовые добавки и пищевой краситель. Указанный рабочий раствор обладает важным свойством образовывать гели при нагревании. При создании оптимальных условий термообработки получаемые белковые гели характеризуются изотропной структурой [1]. Пищевой кра- 
ситель можно получать путем экстракции необходимых компонентов из натурального растительного сырья. Для этой цели могут использоваться аппараты для пневмо-пульсационного воздействия на жидкие системы [2].

Рабочий белоксодержащий раствор, обладающий свойством образовывать гели при нагревании и содержащий необходимые вкусовые добавки, подлежит тщательной гомогенизации. Для этого целесообразно использовать роторно-пульсационные аппараты, которые зарекомендовали себя как эффективные устройства для создания однородных устойчивых эмульсий [3-7].

Приготовленный гомогенный раствор направляется в устройство для монодисперсного дробления струи жидкости на капли. Принцип работы таких устройств состоит в наложении механических колебаний на сопловую систему, из которой вытекает ламинарная струя жидкости. Данный механизм связан с явлением потери устойчивости течения жидкости при воздействии на поток внешних возмущений [8]. Вибрация сопловой системы с необходимой частотой и амплитудой вызывает потерю устойчивости, деформацию и дробление струи на капли одинакового размера [9].

Образовавшиеся капли направляются для термоформования в грануляционную колонну. Грануляционная колонна является одним из основных элементов оборудования при производстве гранулированных пищевых продуктов. Она представляет собой металлический цилиндр, в котором циркулирует нагретое растительное масло. В его среде происходит гранулообразование, протекающее вследствие процесса гелирования частиц. Начало процесса гелирования связано с достижением каплями требуемой температуры $\left(\sim 60 \ldots 63^{\circ} \mathrm{C}\right)$, при которой начинается термокоагуляция белковых компонентов рабочего раствора, начальная температура которого составляет $20 \ldots 25^{\circ} \mathrm{C}$. Таким образом, высота грануляционной колонны должна быть не менее расстояния $z_{\mathrm{H}}$, которое проходят капли от входа в колонну до той точки, в которой ее температура повышается до температуры начала термокоагуляции. Следует отметить, что термокоагуляция происходит не мгновенно, а на протяжении некоторого отрезка времени, в течение которого должен завершиться указанный сложный физико-химический процесс, обеспечивающий требуемые показатели готового продукта. Поэтому высота колонны должна быть больше, чем величина $z_{\mathrm{H}}$.

Метод исследования. Для нахождения $z_{\mathrm{H}}$ выполняется численное решение сопряженной задача теплообмена капли меланжа в среде нагретого растительного масла в постановке, аналогичной той, что была рассмотрена в $[10,11]$. Динамика жидкости внутри капли и формующей жидкости описывается системой уравнений Навье-Стокса. Теплоперенос в жидкостях описывается уравнением энергии. На границе раздела сред задаются условия четвертого рода. Система указанных уравнений с граничными условиями решается методом конечных разностей. Задача решается с учетом зависимости вязкости жидкостей от температуры. Вязкость растительного масла значительно уменьшается при увеличении температуры от $20{ }^{\circ} \mathrm{C}$ до $70{ }^{\circ} \mathrm{C}$.

Как было показано в работах $[10,11]$, характер движения жидкости внутри капли циркуляционный. Гидродинамическое сопротивление жидкой капли в формующей среде ниже, чем у твердой частицы такого же диаметра. Однако это имеет место лишь до того момента времени, пока поверхность капли в результате термокоагуляции не начинает затвердевать. После достижения поверхностью капли температуры $63^{\circ} \mathrm{C}$ начинается процесс термокоагуляции белка, в результате которого жидкая капля трансформируется в квазитвердое тело. Это происходит на протяжении определенного промежутка времени, в течение которого вещество капли можно приближенно считать жидкостью с вязкостью, стремительно растущей, но ограниченной. Такая модель принимается для решения сопряженной задача теплообмена капли на той стадии, когда температура ее поверхности начинает превалировать над температурой начала термокоагуляции.

Результаты исследований. Результаты расчета скорости движения центра массы капли диаметром $D_{\mathrm{K}}=2,8$ мм от времени и расстояния, на которое она при этом переместилась, представлены на рис.1. Как видно из рисунка (кривая 1), скорость капли после стремительного повышения в начальный период времени сначала стабилизируется, а затем начинает уменьшаться и после этого асимптотически выходит на постоянную величину ( $\left.w_{\mathrm{\kappa}} \approx 0,045 \mathrm{~m} / \mathrm{c}\right)$. Связано это с изменением во времени вязкостей формующей среды и вещества капли. На заключительной стадии термоформования жидкость капли у ее поверхности практически переходит в твердое состояние. Постепенно в это же состояние трансформируются и внутренние слои капли. Внутреннее циркуляционное движение при этом прекращается, а сила гидродинамического сопротивления, действующая на каплю, увеличивается. Вследствие этого уменьшается скорость движения центра массы капли. Также при этом уменьшается и интенсивность теплопереноса от формующей среды к капле. Зависимость среднеобъемной температуры капли от времени представлена на рис. 2.

Как видно из рис. 2, процесс формования гранулы начинается уже после первой секунды пребывания капли в формующей среде. Исключая из представленных на рис. 1 и рис. 2 зависимостей $z_{\mathrm{\kappa}}(\tau)$ и $t(\tau)$ время $\tau$, можно получить зависимость $t\left(z_{\kappa}\right)$ (рис.3), из которой определяется расстояние $z_{\kappa}$, пройденное частицей внутри колонны до момента начала ее термоформования. В данном случае оно составляет $z_{\mathrm{\kappa}}^{*} \approx 0,05$ м. 


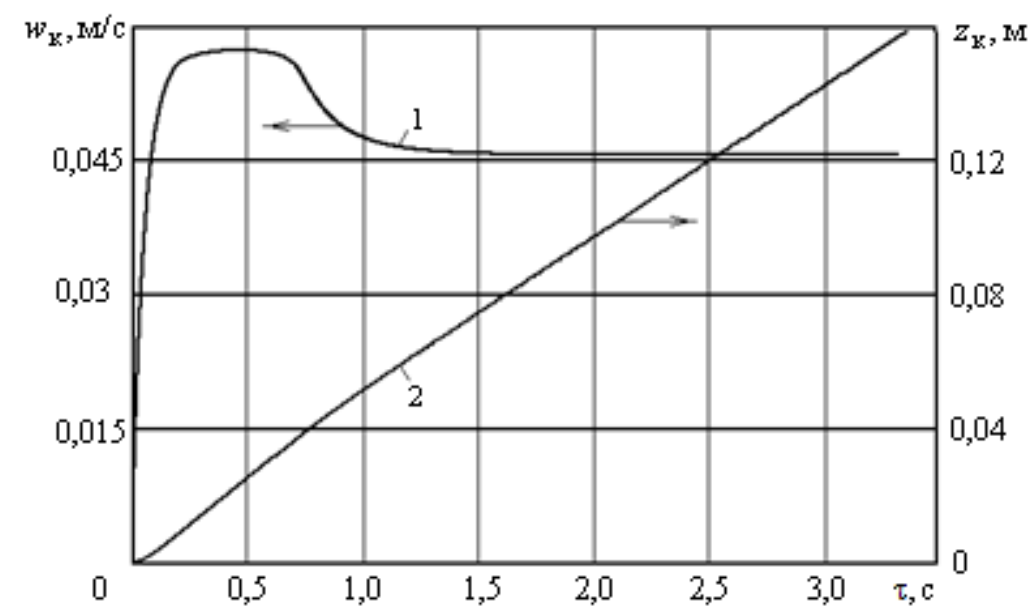

Рис. 1. Зависимость скорости капли и расстояния, пройденного каплей, от времени.

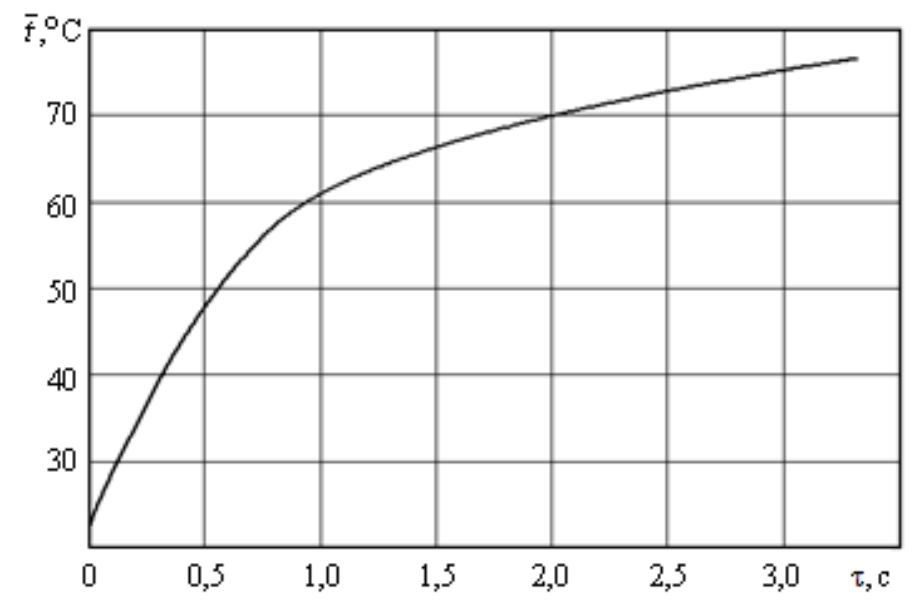

Рис. 2. Зависимость среднеобъемной температуры капли от времени

Высота колонны должна быть, по крайней мере, не меньше указанной величины $z_{\kappa}^{*}$. На самом же деле она должна быть существенно больше, чтобы процесс гелирования успел завершиться. Следует также иметь в виду, что величина $z_{\kappa}^{*}$ рассматривается в системе отсчета, связанной с движущейся формующей средой. Поэтому, реальное расстояние $z^{*}$, отсчитываемое от выходного сечения колонны, необходимо определять, как $z^{*}=-z_{\mathrm{\kappa}}{ }^{*}-V_{0} \tau$, где $V_{0}-$ среднеобъемная скорость течения формующей среды в колонне.

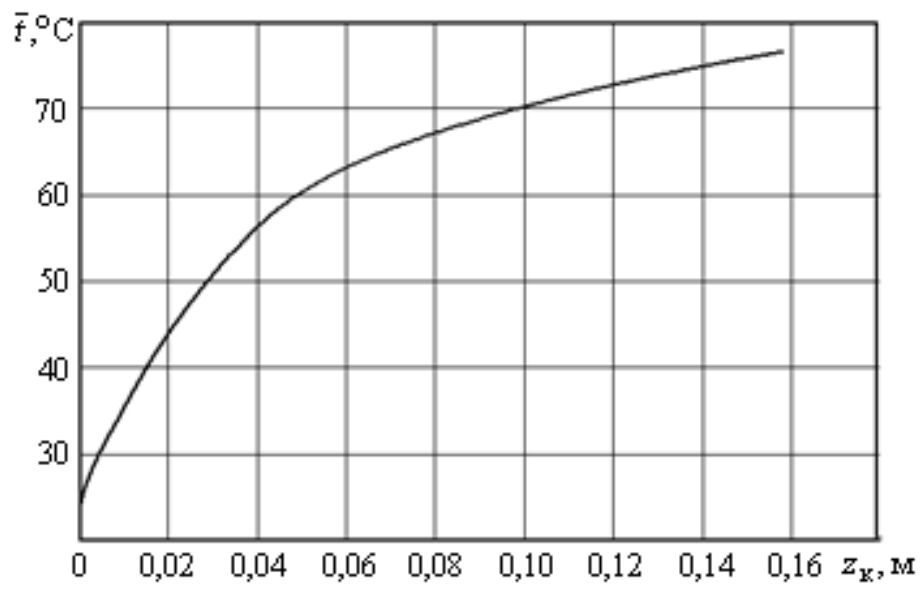

Рис. 3. Зависимость температуры капли от расстояния, пройденного каплей. 
Как видно из рис. 3 , при $z_{\mathrm{K}}^{*}>0,16$ м температура частицы начинает уже незначительно отличаться от температуры формующей среды и теплообмен между ними практически прекращается.

Важной проблемой, возникающей при проектировании грануляционной колонны, является снижение потерь теплоты с ее наружной поверхности. При проектировании системы теплоизоляции колонны необходимо использовать данные об уровнях указанных потерь теплоты. Эти данные могут быть получены из решения сопряженной задачи теплопереноса от потока нагретой формующей жидкости в колонне к окружающей воздушной среде. Задача описывается системой уравнений гидродинамики и теплопереноса в формующей среде и уравнением теплопроводности для колонны. Система уравнений решается численно методом конечных разностей с использованием метода матричной прогонки [12]. Расчеты полей скорости и температуры жидкости в грануляционной колонне выполнялись для начальной скорости жидкости $V_{0}=0,005$ м/с, начальной температуры $t_{0}=92{ }^{\circ} \mathrm{C}$ и температуры наружного воздуха $t_{\infty}=20{ }^{\circ} \mathrm{C}$.

Обсуждение результатов. Как показали результаты расчетов, температура формующей среды за счет потерь теплоты в окружающее пространство существенно снижается около внутренней поверхности колонны. Течение жидкости практически всюду опускное, за исключением небольшой области у стенки колонны около входа потока в коническое сужение, где устанавливается циркуляционное течение. В этой же зоне теплоперенос от жидкости к стенке колонны интенсифицируется, что приводит к понижению ее температуры около стенок до $65^{\circ} \mathrm{C}$. Для рассмотренного режима течения и теплопереноса суммарные тепловые потоки, отводимые от формующей среды, составляют: тепловой поток, расходуемый на нагрев частиц 20 Вт; потери теплоты в окружающее пространство 132 Вт. При этом среднемассовая температура жидкости на выходе из колонны снижается до $80{ }^{\circ} \mathrm{C}$.

Как следует из представленных результатов, отсутствие теплоизоляции на внешней поверхности грануляционной колонны приводит к значительным потерям теплоты в окружающее пространство, что делает данный процесс производства гранулированных белоксодержащих продуктов весьма энергозатратным. Одним из очевидных путей снижения потерь теплопы является установка теплоизоляции на колонне. Рассмотрим для сравнения результаты решение той же задачи, но при условии, что колонна теплоизолированная. Теплопроводность изоляционного материала составляет $\lambda_{\text {и }}=0,1$ Вт/(м·К), а его толщина равна 4 мм. Как показали результаты решения данной задачи, при наличии теплоизоляции суммарный поток теплоты в окружающее пространство снижается до 114 Вт (на 15\%), а температура масла на выходе из колонны увеличивается до $82{ }^{\circ} \mathrm{C}$. Сравнение результатов расчета распределений температур и плотностей тепловых потоков по внешней теплоотдающей поверхности колонны, полученных для двух вариантов ее исполнения, представлены на рис. 4, 5.

Из рис.4 видно, что у колонны с теплоизоляцией температура наружной поверхности на $5 \ldots 12{ }^{\circ} \mathrm{C}$ ниже, чем у колонны без теплоизоляции. Наибольшее отличие температуры на поверхностях колонны наблюдается у ее горловины $\left(z=z_{\max }\right)$, через которую в колонну подается разогретый теплоноситель. Если в этой области температура колонны без теплоизоляции практически равна температуре формующей среды, то у теплоизолированной колонны она оказывается ниже ее температуры на $12{ }^{\circ} \mathrm{C}$.

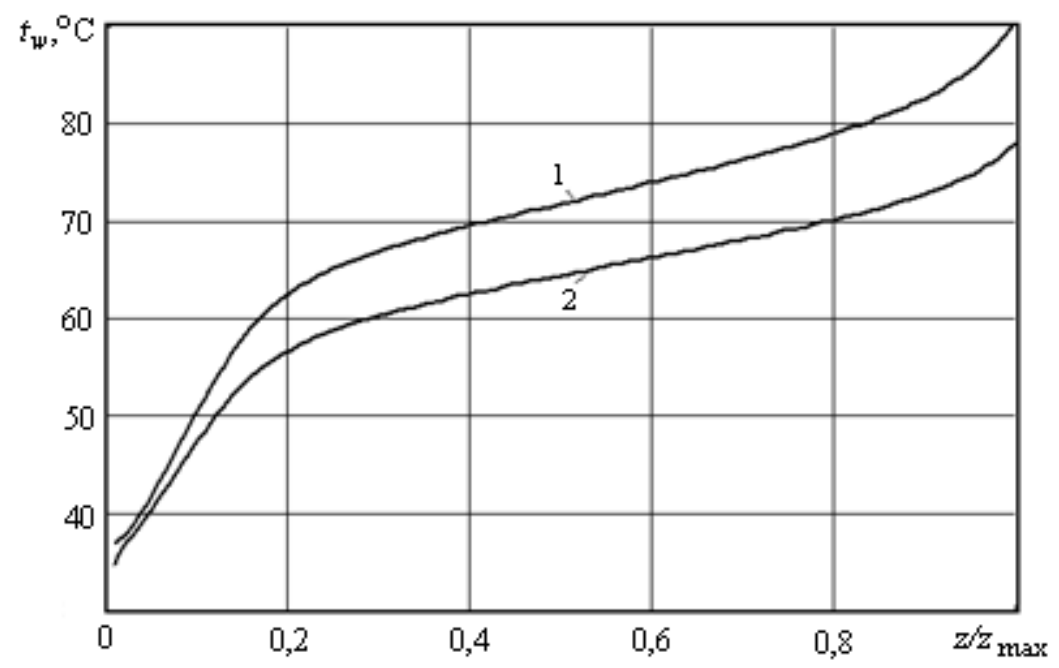

Рис. 4. Распределения температуры по внешней поверхности колонны:

1 - колонна без теплоизоляции; 2 - колонна теплоизолированная 


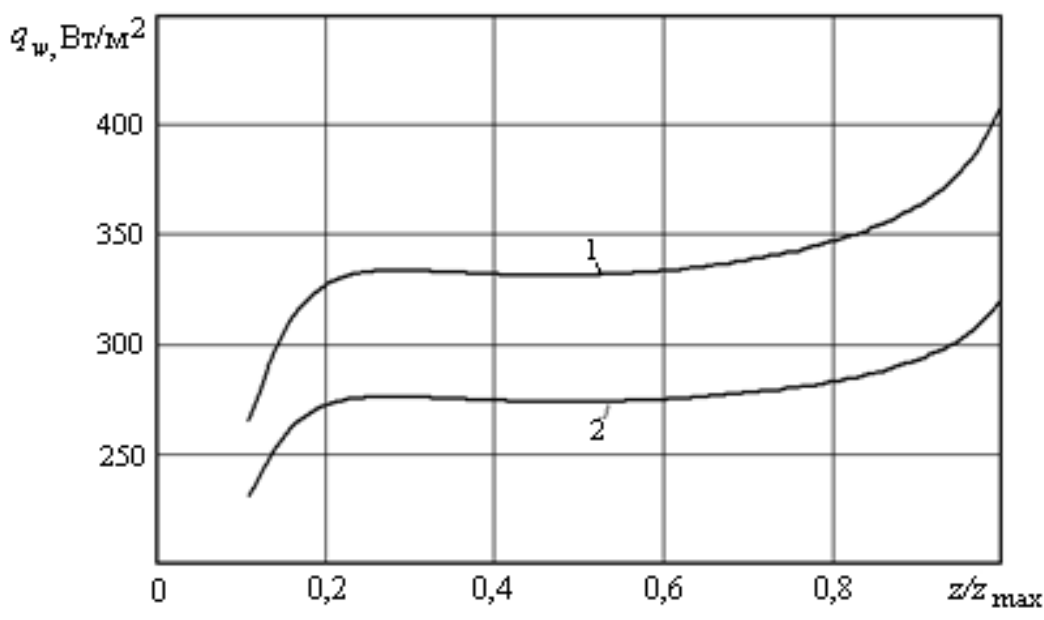

Рис. 5. Распределения плотностей теплового потока по поверхности колонны: 1 - колонна без теплоизоляции; 2 - колонна теплоизолированная

Как видно из рис.5, в средней части грануляционной колонны плотность теплового потока за счет установления теплоизоляции снижается на $50 \ldots 65 \mathrm{BT} / \mathrm{M}^{2} \mathrm{~K}$, что способствует повышению энергетической эффективности производства имитированной черной икры методом термоформования.

Выводы. Как показали результаты численных исследований температурного режима грануляционной колонны при производстве имитированных гранулированных пищевых продуктов, установка теплоизоляции толщиной 4 мм с коэффициентом теплопроводности 0,1 Вт/(м·К) на поверхности грануляционной колонны позволяет снизить потери теплоты с 132 Вт до 114 Вт (на 15\%). Температура формующей жидкости на выходе из грануляционной колонны при этом повышается от $80{ }^{\circ} \mathrm{C}$ до $82{ }^{\circ} \mathrm{C}$. Однако, более эффективным способом ограничения тепловых потерь будет, по-видимому, установка на колонне воздушной рубашки, что в последнее время и практикуется при создании оборудования по производству гранулированных пищевых продуктов.

\section{References}

1. Pivovarov, P. P., Zakharenko, V. A., Kucheruk, Z. I. (1991) Poristost' belkovykh geley, poluchayemykh putem termoobrabotki. Izvestiya vysshikh uchebnykh zavedeniy. Pishchevaya tekhnologiya, (1-3), $79-80$.

2. Basok, B.I., Novitskaya, M.P., Chayka, A.I. (2014) Gidrodinamika i teploobmen pri pnevmo-pul'satsionnom vozdeystvii na zhidkiye sistemy. Kyiv, 298.

3. Basok, B.I., Davydenko, B.V., Avramenko, A.A., Pirozhenko, I.A. (2012). Gidrodinamika, teploobmen i effekty drobleniya vo vraschatelno-pulsiruyuschih potokah. Kyiv, 298.

4. Pavlenko, A.M., Basok, B.I. (2009) Strukturoobrazovaniye i dezintegratsiya emul'siy v vikhrevykh apparatakh. Dneprodzerzhinsk,. 205.

5. Dolinskiy, A.A., Pavlenko, A.M., Basok, B.I. (2005) Teplofizicheskiye protsessy v emul'siyakh. Kiyev,. 140.

6. Nakorchevskiy, A.I., Basok, B.I. (2001) Gidrodinamika i teplomassoperenos v geterogennykh sistemakh i pul'siruyushchikh potokakh. Kyiv,.208.

7. Dolinskiy, A.A., Basok, B.I., Gulyy, S.I. (1996) Diskretno-impul'snyy vvod energii v teplotekhnologiyakh. Kyiv, 208

8. Basok, B. I., Gotsulenko, V.V. (2015) Termogidrodinamicheskaya neustoychivost' potoka teplonositelya. Kyiv, 307.

9. Kremnev, O. A., Kravchenko, YU. S. (1975) Nekotoryye osobennosti vynuzhdennogo raspada struy zhidkosti v kapillyarnom rezhime. Doklady AN USSR, ser. A, (6). 524-528.

10. Kravchenko, YU., Davydenko, B. (2002) Nestatsionarnyy teploobmen sfericheskoy kapli, dvizhushcheysya v vyazkoy srede pod deystviyem sily tyazhesti. Promyshlennaya teplotekhnika, 24(5), 11 - 16.

11. Kravchenko YU., Davydenko B., Teslya A. (2003) Dvizheniye sfericheskoy kapli v vyazkoy srede pod deystviyem sily tyazhesti. Promyshlennaya teplotekhnika, 25(4). $20-25$.

12. Davydenko, B. (2008) Metod matrichnoy progonki dlya resheniya setochnykh uravneniy gidrodinamiki. Vostochno-Yevropeyskiy zhurnal peredovykh tekhnologiy, 5(5). 2008. 7-11.

Отримано в редакцію 15.04.2019

Прийнято до друку 22.06.2019
Received 15.04.2019

Approved 22.06.2019 